\title{
Influence of intermittent administration of parathyroid hormone on muscle tissue and bone healing in orchiectomized rats or controls
}

\author{
Marina Komrakova, Carsten Krischek ${ }^{1}$, Michael Wicke ${ }^{2}$, Stephan Sehmisch, Mohammad Tezval, \\ Maximillian Rohrberg, Thomas Brandsch, Klaus M Stuermer and Ewa K Stuermer
}

Department of Trauma Surgery and Reconstructive Surgery, University of Goettingen, Robert-Koch 40, 37075 Goettingen, Germany

${ }^{1}$ Institute of Food Quality and Safety, University of Animal Medicine, Bischofsholer Damm 15, 30173 Hannover, Germany

${ }^{2}$ Department of Animal Sciences, University of Goettingen, Albrecht-Thaer-Weg 3, 37075 Goettingen, Germany

(Correspondence should be addressed to M Komrakova; Email: komrakova@yahoo.com)

\begin{abstract}
Influence of human parathyroid hormone (hPTH 1-34) on muscle and bone healing was studied in either orchiectomized (Orx at 8 months of age) or sham-operated male rats. Eleven-month-old Sprague-Dawley rats underwent bilateral transverse metaphyseal osteotomy of tibia and were divided into four groups $(n=12)$ : 1$)$ sham-vehicle, 2$)$ sham group-PTH everyday, 3) Orx-vehicle, 4) Orx-PTH everyday, and 5) Orx-PTH every other day. PTH dosage was $40 \mu \mathrm{g} / \mathrm{kg}$ body weight. After 5 weeks, fiber cross-sectional area, capillary density, and enzyme activity (lactate dehydrogenase, citrate synthase, and complex I) were measured in soleus (MS), gastrocnemius (MG), and longissimus (ML) muscles; tibiae were analyzed by computed tomographical, histological, and gene expression analyses. The effect of PTH in all rats was increased serum osteocalcin, cortical and callus
\end{abstract}

densities and callus area. In sham rats capillary density was increased in limb muscles (MS: 1.3-1.7, MG: 1.2-1.4 capillaries/fiber), and rate of osseous bridging of osteotomy was enhanced (67-100\%). In Orx rats serum creatine kinase was decreased (6670-2847 U/1), and bone genes (Igf-1, osteoprotegerin, and receptor activator of nuclear factor $\mathrm{kB}$ ligand) were up-regulated. Cross-sectional area, enzyme activity, food intake, weight of body, visceral organs, adipose tissue, MG, and MS were not affected by PTH. PTH had a favorable effect on muscle capillary density and improved bone healing being more effective in sham rats and having no adverse systemic effect. The effect was less if PTH was applied every other day. The findings may show up trends for therapeutic treatment of male patients.

Journal of Endocrinology (2011) 209, 9-19

\section{Introduction}

Intermittently administered human parathyroid hormone (hPTH (1-34)) is the only clinically approved bone anabolic therapy for osteoporotic patients of both genders (Gagnon et al. 2008). PTH regulates serum calcium by acting mainly on bone and kidney and stimulating calcium re-absorption and bone resorption in the situation of low serum calcium levels (Partridge et al. 2006). Intermittent exposure to PTH as once daily injections increased bone formation over resorption. Recent studies have demonstrated that intermittent administration of PTH enhanced fracture healing in experimental animals (Barnes et al. 2008, Komrakova et al. 2010). Since the osteoporotic are most commonly seen as postmenopausal and senile, the majority of research on osteoporosis has focused on women, though it is also becoming an important problem in men. Hypogonadism in young men and agerelated decline in gonadal hormone levels in older men are associated with the development of senile osteoporosis
(Gagnon et al. 2008). Gonadal androgens exert a wide variety of physiological and morphological effects in organisms (Meisel \& Sachs 1994). Androgen deficiency causes the loss of muscle weight and induces atrophy in muscles (Jiang \& Klueber 1989). Testosterone replacement increases skeletal muscle mass and lowers body fat levels in hypogonadal men (Bhasin et al. 1997).

Applying PTH to improve bone quality or fracture healing in osteoporotic organism, it is also important to investigate the effects of PTH treatment on muscle tissue that is functionally linked to the bones. A single injection of PTH caused a rapid decrease in serum calcium followed by a rapid recovery to baseline values (Frolik et al. 2003). As calcium has a central role in muscle function, it is conceivable that alternations of serum calcium levels affect muscle tissue. Furthermore, excess of PTH itself appears to have detrimental effects on skeletal muscle metabolism, since it has been shown that hyperparathyroidism is associated with muscle dysfunction (Shin \& Stern 1967, Garber 1983, Baczynski et al. 1985). A reason 
might be that PTH impairs production, transfer, and utilization of energy in rat skeletal muscle (Baczynski et al. 1985). High serum levels of PTH were associated with loss of muscle strength and muscle mass in humans (Visser et al. 2003). In a recent study in our working group, it was shown that PTH administered intermittently had no effect on mitochondrial respiratory activity and muscle structure of gastrocnemius muscle in both healthy and ovariectomized (Ovx) female rats of 6 months of age (Komrakova et al. 2010). However, it is known that aging affects muscle tissue differently in females and males (Phillips et al. 1993). Furthermore, gender- and muscle-specific differences were observed in the regulation of fiber types by thyroid hormones (Larsson \& Yu 1997). After PTH administration, these differences may also be found. We are not aware of the influence of PTH applied to improve fracture healing on skeletal muscles in male organism.

The present study was undertaken to investigate the effect of PTH administration on structure and metabolism of soleus (MS), gastrocnemius (MG), and longissimus (ML) muscles of 12-month-old male rats either orchiectomized (Orx) or sham operated undergoing tibia-healing period. The current study gives an account of bone-healing process.

\section{Materials and Methods}

The animal study protocol was approved by the local regional government and conformed to German animal protection laws (permission from 12/05/03, Az: 509.42502/01-53.03 District Government of Braunschweig). All chemicals were obtained from Sigma-Aldrich Chemie $\mathrm{GmbH}$ unless otherwise indicated.

Sixty 8-month-old male Sprague-Dawley rats were obtained from Janvier (Le Genest-Saint-Isle, France). Under i.p. ketamine (Medistar, Holzwickede, Germany) and xylazine (Riemser, Greifswald, Germany) anesthesia (60 mg and $8 \mathrm{mg} / \mathrm{kg}$ of body weight (BW) respectively), 24 rats were sham operated (sham), and 36 rats were bilaterally Orx. Rats were housed three to four in standard cages under $12 \mathrm{~h}$ light: $12 \mathrm{~h}$ darkness regimes at a constant temperature of $22 \pm 1{ }^{\circ} \mathrm{C}$. Rats received standard pelleted diet (Ssniff special diet $\mathrm{GmbH}$, Soest, Germany) throughout the experiment. BW of rats and food intake were recorded weekly. All animals had free access to food and water throughout the experiment.

After 12 weeks (Fig. 1), all rats underwent a bilateral metaphyseal osteotomy of tibia (Stuermer et al. 2010). Briefly, under ketamine/xylazine anesthesia, rats received subcutaneously decentan (Merck) and rimadyl (Pfizer, Karlsruhe, Germany) (5 $\mathrm{mg}$ and $4 \mathrm{mg} / \mathrm{kg} \mathrm{BW}$ respectively). Thereafter, a transverse osteotomy was created using an ultrasound saw (Piezosurgery, Mectron Medical Technology, Carasco, Italy). Tibia fragments were fixed with the aid of a T-titan plate and four screws (Stryker Trauma, Selzach, Switzerland).

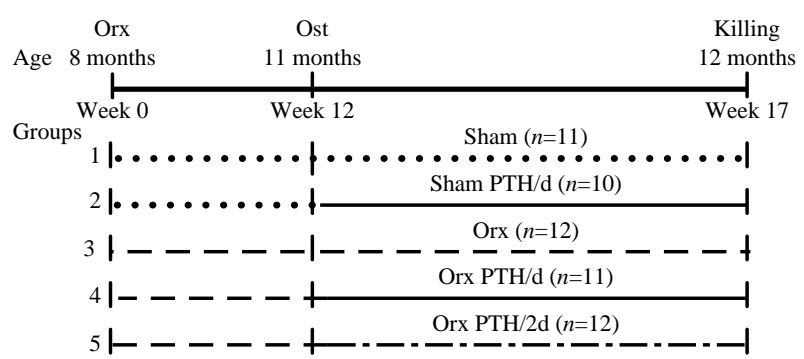

Figure 1 Schematic flowchart of the experiment. Eight-month-old male rats were either orchiectomized (Orx) or sham operated (week $0)$. After 3 months, all rats underwent bilateral osteotomy of tibia (Ost, week 12) and were divided into groups $(n=12)$ that were either treated with s.c. PTH ( $40 \mu \mathrm{g} / \mathrm{kg}$ BW per day) everyday (PTH/d) or every other day (PTH/2d) or treated with vehicle for up to 5 weeks (week 17). Dotted line, sham orchiectomy; dashed line, Orx; continuous line, PTH/d; dot-and-dash line, PTH/2d; $n$, number of rats survived to the end of experiment.

After osteotomy, rats were divided into five groups (12 rats each). In group 1, sham-operated rats were given vehicle everyday $(0.9 \% \mathrm{NaCl}$; sham). In group 2 , sham-operated rats were treated with PTH everyday (sham PTH/d). In group 3, Orx rats were given vehicle (Orx). In group 4, Orx rats were treated with PTH everyday (Orx PTH/d). In group 5, Orx rats were given PTH every other day (Orx PTH/2d). All injections were done subcutaneously from the first day after osteotomy. A single dosage of PTH was $40 \mu \mathrm{g} / \mathrm{kg}$ BW. Newly formed callus was labeled by fluorescence dyes, which were injected subcutaneously (Rahn 1976). Xylenol orange $(90 \mathrm{mg} / \mathrm{kg} \mathrm{BW})$ was injected on day 13 , calcein green $(10 \mathrm{mg} / \mathrm{kg} \mathrm{BW})$ was injected on day 18 , and alizarin complexone $(30 \mathrm{mg} / \mathrm{kg} \mathrm{BW})$ was injected on days 22 and 24 after osteotomy respectively. Tetracycline $(25 \mathrm{mg} / \mathrm{kg} \mathrm{BW})$ was injected $1 \mathrm{~h}$ prior to decapitation, i.e. 5 weeks after osteotomy (Fig. 1).

Blood samples $(0 \cdot 5-1 \cdot 0 \mathrm{ml})$ were collected at the time of orchiectomy and osteotomy by penetrating the retro-orbital sinus with a glass capillary tube and used for the analyses of serum testosterone level.

Animals were decapitated under $\mathrm{CO}_{2}$ anesthesia 5 weeks after osteotomy (Fig. 1). Blood samples were collected for analyses of serum testosterone, osteocalcin (Oc), alkaline phosphatase (Alp), and creatine kinase (CK) levels. Heart, liver, kidney, spleen, and visceral adipose tissue were extracted and weighed. The presence of testes has been additionally checked.

Samples of MG, MS and ML were randomly collected from either left or right side immediately after decapitation of rats. A block of ML $\left(1 \mathrm{~cm}^{3}\right)$ was excised at the level of the last rib. The entire MG and MS were carefully excised, weighted, pinned at both ends, and cut in the middle across the muscle. Thereafter, muscle samples were removed from the center of the ML, MG, and MS, frozen directly in liquid nitrogen, and stored at $-80{ }^{\circ} \mathrm{C}$ until either histological or enzyme analyses. The three different muscles were chosen because of their different muscle fiber-type composition. Enzyme analyses 
were performed only with samples from the ML and MS, as these muscles have different localizations and clearly differ in muscle fiber composition (Schwartz-Giblin et al. 1983, Armstrong \& Phelps 1984).

Tibiae either left or right were dissected and freed of soft tissues. Plates and screws were extracted. One tibia chosen randomly was stored at $-20^{\circ} \mathrm{C}$ for flat-panel volume-computed tomographic (fpVCT) and histomorphological analyses. Metaphyseal clips of other tibia containing newly formed callus were stored at $-80{ }^{\circ} \mathrm{C}$ for gene expression analyses.

\section{Serum analyses}

Serum analyses were conducted at the Department of Clinical Chemistry, University of Goettingen. Serum testosterone level was measured using liquid chromatography tandem mass spectrometry with the aid of a Quattro Premier XE Micromass-System (Waters Corp., Milford, MA, USA) (Streit et al. 2007). Serum CK was detected by the 'reverse reaction' and activation by acetylcysteine. OC was determined by electrochemiluminiscence immunoassay analyses and ALP by colorimetric assay. Analyses were done using automated chemistry analyzer (Roche/Hitachi Modular) and commercially available kits (Roche) according to the manufacturer's instructions (Roche Diagnostics $\mathrm{GmbH}$ ). In vitro assays are assigned for determination of CK, ALP, and OC in human serum. Inter-assay coefficient of variation $(\mathrm{CV})$ was $0 \cdot 7,1 \cdot 4$, and $1 \cdot 5 \%$, and intra-assay $\mathrm{CV}$ was $0 \cdot 6,0 \cdot 6$, and $0 \cdot 7 \%$ for ALP, $\mathrm{CK}$, and $\mathrm{OC}$ assays respectively (Roche). Sensitivity was $0.67 \mathrm{U} / \mathrm{l}, 3 \mathrm{U} / \mathrm{l}$, and $0.50 \mathrm{ng} / \mathrm{ml}$ for ALP, CK, and OC respectively (Roche).

\section{Analyses of muscle fibers and capillary density}

Serial cross sections of $12 \mu \mathrm{m}$ were cut from the removed samples of the three muscles using a cryostat (Leica, Frigocut $2800 \mathrm{E}$, Nussloch, Germany) at $-20^{\circ} \mathrm{C}$ and mounted on glass slides. For the analysis of muscle fibers, sections were fixed in $1 \%$ paraformaldehyde solution ( $\mathrm{pH} 6 \cdot 6$ ) containing $1 \% \mathrm{CaCl}_{2}$ and $6 \%$ sucrose and then stained by incubation in reduced NADH-diaphorase solution $(\mathrm{pH} 7 \cdot 4)$ followed by acidic incubation ( $\mathrm{pH} 4 \cdot 2)$ and incubation in adenosine- $5^{\prime}-$ triphosphate solution ( $\mathrm{pH}$ 9・4) (Horák 1983). Muscle fibers were classified into fast-twitch glycolytic $(G)$, fast-twitch oxidative, and slow-twitch oxidative according to Peter et al. (1972). The two oxidative (O) fiber types were not always clearly distinguished and, therefore, were analyzed together. The MS mainly consists of $\mathrm{O}$ fibers (Armstrong \& Phelps 1984). Cross-sectional area of at least $60 \mathrm{O}$ and $\mathrm{G}$ fibers determined within two fields of the cross section (30 fibers per field) was measured.

For the analysis of muscle capillaries, sections were fixed for $1 \mathrm{~h}$ in $100 \%$ ethanol/chloroform/glacial acid at a ratio of 16:3:1 at $4{ }^{\circ} \mathrm{C}$. Thereafter, PAS staining method (Andersen 1975) was applied to stain the blood vessels. Briefly, after incubation in $0.3 \% \alpha$-amylase (from porcine pancreas) solution, sections were treated with $1 \%$ periodic acid and stained in Schiff's Reagent solution (Roth, Karlsruhe, Germany). Finally, sections were treated with 10\% potassium sulfite solution. Capillaries and fibers found in three randomly selected fields $\left(1 \mathrm{~mm}^{2}\right.$ each) within cross section were counted. The ratio of capillaries to muscle fiber was taken in the analyses.

The measurements were done with the aid of a digital camera (DVC 1310 C, DVC Company, Maidenhead, UK) and a microscope (Eclipse E 600, Nikon, Japan) at a magnification of $\times 10$ using a computerized image analysis program (Lucia G, Laboratory Imaging, Version 4.82, Praha, Czech Republic).

\section{Enzyme analyses}

Muscle samples were weighed and homogenized in ice-cold Chappell-Perry medium $(0 \cdot 1 \mathrm{M} \mathrm{KCl}, 0 \cdot 05 \mathrm{M}$ Tris, $0 \cdot 01 \mathrm{M}$ $\mathrm{MgCl}_{2} \times 6 \mathrm{H}_{2} \mathrm{O}$, and $1 \mathrm{mM}$ EGTA, pH 7.5) using a PotterS-homogenisator (B.Braun Biotech International, Melsungen, Germany) and kept on ice between measurements. Aliquots were frozen for measurements of protein content. Enzyme activities were assayed using a spectrophotometer (Spectronic Genesys 2PC, Pittsford, NY, USA) and WinSpec software (Spectronic Instruments). The assays were performed in triplicates at $30^{\circ} \mathrm{C}$ over $5 \mathrm{~min}$ and a $\mathrm{pH}$ of $7 \cdot 4$ unless otherwise indicated. The analysis was done within $2 \mathrm{~h}$ after tissue had been initially homogenized. The enzyme activities of the lactate dehydrogenase (LDH, EC 1.1.1.27) are expressed in $\mathrm{U} / \mathrm{mg}$ protein and the enzyme activities of the citrate synthase (CS, EC 2.3.3.1) and NADHubiquinone oxidoreductase (complex I, EC 1.6.5.3) are expressed in $\mathrm{U} / \mathrm{g}$ protein.

In glycolysis, LDH catalyzes the reduction of pyruvate $(1.2 \mathrm{mM})$ to lactate accompanied with the oxidation of $\mathrm{NADH}(150 \mu \mathrm{M})$ to $\mathrm{NAD}^{+}$. In the enzyme activity assay, the oxidation of NADH results in the time-dependent reduction of absorption at $340 \mathrm{~nm}$, as $\mathrm{NAD}^{+}$shows no absorption at this wavelength.

CS activity was assayed according to Faloona \& Srere (1969). In the citrate cycle, CS catalyzes the condensation of acetyl-coenzyme A (CoA) $(0.1 \mathrm{mM})$ and oxalacetate $(0.5 \mathrm{mM})$ to citrate accompanied with the liberation of CoA. In the enzyme activity assay, the liberated CoA molecules irreversibly bind to 5,5'-dithiobis (2-nitrobenzoic acid) (DTNB, $0.1 \mathrm{mM}$ ) forming thionitrobenzoic acid. The time-dependent increase of the latter product was followed at $412 \mathrm{~nm}$, as the thionitrobenzoic acid absorbs the light at this wavelength. The detergent Triton X-100 (0.1\%) was added to the incubation solution for disintegration of all mitochondria and liberation of all CS proteins.

The complex I activity was assayed according to Hatefi \& Stiggall (1978). In the electron transport chain, complex I catalyzes the oxidation of NADH $(0.2 \mathrm{mM})$ to $\mathrm{NAD}^{+}$ accompanied with the reduction of ubiquinone (CoQ) 
$(0 \cdot 12 \mathrm{mM})$ to dihydroubiquinone $\left(\mathrm{CoQH}_{2}\right)$. The enzyme activity was analyzed at $340 \mathrm{~nm}$. The assay was initially performed over $10 \mathrm{~min}$, and subsequently, the complex I inhibitor rotenone $(10 \mu \mathrm{M})$ was added to incubation solution before the assay was carried out for a further $10 \mathrm{~min}$. Rotenone was added to control the complex I-independent processes of NADH reduction. Complex I activity was calculated by deducting the enzyme activity with rotenone from the total activity. To inhibit further steps of the electron transport chain, the complex III inhibitor antimycin A $(1.0 \mu \mathrm{M})$ and cytochrome oxidase inhibitor potassium cyanide $(1 \mathrm{mM})$ were added to the incubation solution.

Protein content was determined in frozen-thawed aliquot using multilabel reader (Perkin Elmer Precisely Victor X4, Turku, Finland) and software version 4.0 (Perkin Elmer Life and Analytical Science). BCA Protein Assay Kit based on bicinchoninic acid for the colorimetric detection and quantification of proteins was used according to the manufacturer's protocol (Pierce, Rockford, IL, USA).

\section{Analyses of bone healing}

FpVCT analysis has been done in vitro after extraction of plate and screws. Tibia was thawed and analyzed using an fpVC tomograph (GE Global Research, Niskayuna, NY, USA), a non-clinical CT prototype (Missbach-Guentner et al. 2007). Data analysis was done on an Advantage Workstation (version 4.2, General Electric Health Care, Milwaukee, WI, USA). The measurement area extended $2 \mathrm{~mm}$ proximally and $2 \mathrm{~mm}$ distally from the osteotomy site. Callus and cortical ( $\mathrm{Cl}$. and $\mathrm{Ct}$.) densities were initially assessed in Hounsfield units (HU) and then converted into bone mineral density (Cl.BMD and Ct.BMD, $\mathrm{mg} / \mathrm{cm}^{3}$ ) with the aid of hydroxyapatite standards of several mineral densities.

Thereafter, the entire tibia was subjected to the sequential ascending concentrations of ethanol and embedded in methylmethacrylate (Merck). Sections of $150 \mu \mathrm{m}$ thickness were cut longitudinally at right angle to the implant bed using Leica SP 1600 diamond saw microtome (Leica Instruments $\mathrm{GmbH}$, Nussloch, Germany). Osseous bridging of the osteotomy gap was analyzed using at least 10 fluorochrome labeled sections (Fig. 2) with the aid of a Leica microscope (Leitz DM RXE; Leica Mikroskopie \& Systeme GmbH, Wetzlar, Germany). Calcein green stained area was built within 13 and 18 days after osteotomy, alizarin complexonestained tissue was formed from 18 to 24 days, and tetracycline-stained tissue was formed within 24 and 35 days after osteotomy (Komrakova et al. 2010).

Three representative central sections of the tibia were digitalized using a digital camera (Leica DC300F) and a zoom stereomicroscope (Leica MZ75) at a magnification of $\times 16$ with the aid of QWin image analysis program (Leica, Bensheim, Germany). The measurement area was similar to that assessed in fpVCT analyses. It was divided into three regions of interest: 1) plate side, ventral aspect; 2) dorsal aspect; 3) the endosteal part of the tibia (Fig. 2a-e). Callus area $\left(\mu \mathrm{m}^{2}\right)$ was measured according to the regions of interest.
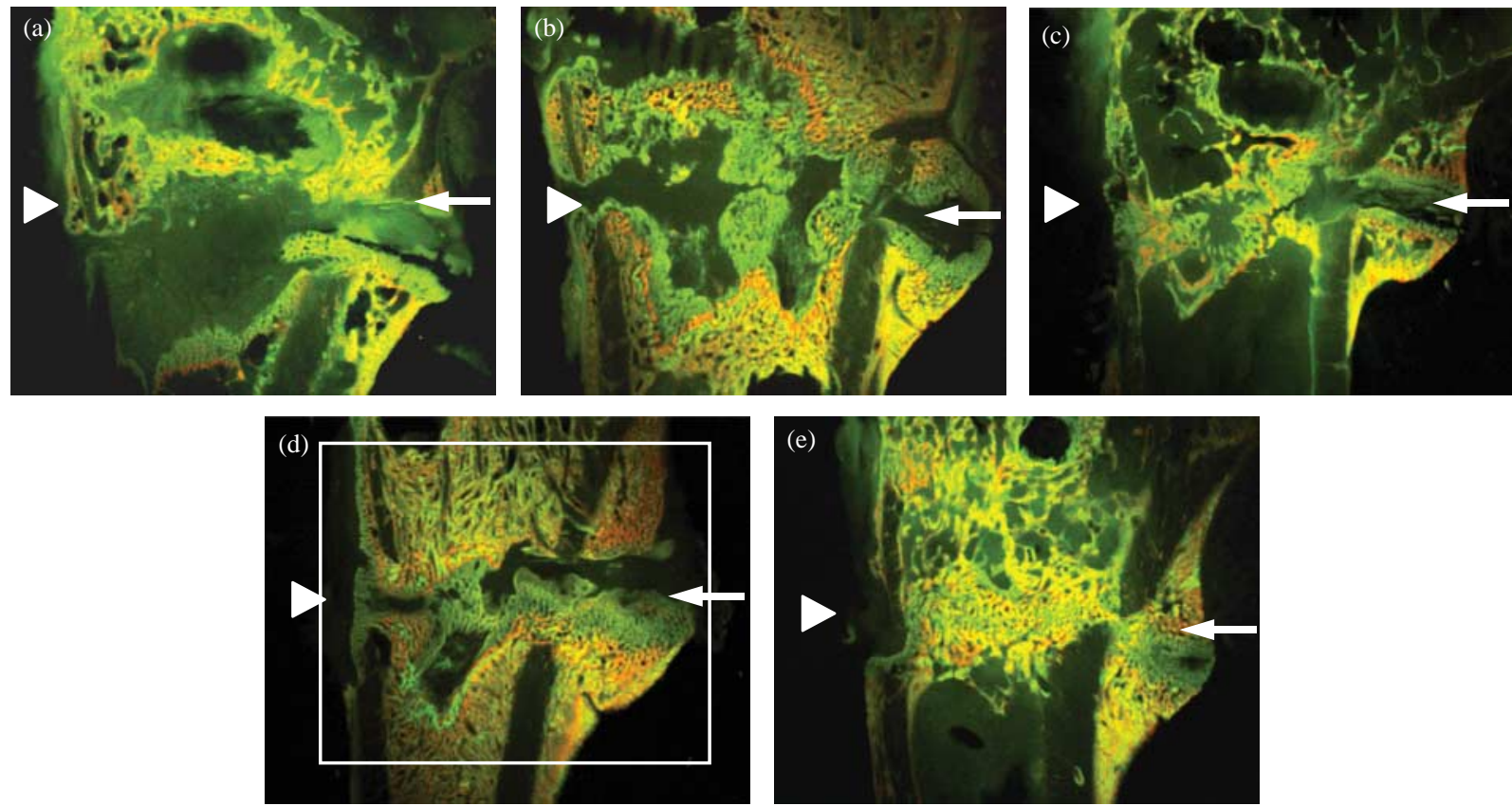

Figure 2 Images of longitudinal sections of tibia metaphysis labeled with fluorochromes made 35 days after osteotomy in treatment groups: (a) sham; (b) sham PTH/d; (c) Orx; (d) Orx PTH/d; (e) Orx PTH/2d. Arrowheads, ventro-medial aspect; arrows, dorsal aspect; rectangular frame, region of interest. 
Analyses of bone gene expression

Metaphyseal clips of the contralateral tibia containing newly formed callus were homogenized using micro-dismembrator S (Sartorius, Goettingen, Germany). Total cellular RNA was extracted using the RNeasy Mini Kit (Qiagen) and quantified with the aid of a photometer (Biometra, Goettingen, Germany). Purity of RNA was checked based on the absorbance ratio at 260 and $280 \mathrm{~nm}$, which ranged from 1.9 to $2 \cdot 2$. The RNA samples $(100 \mathrm{ng})$ were then reverse transcribed using Superscript RNase $\mathrm{H}$ - reverse transcriptase (Promega). Expression of rat genes, Alp1, Oc, insulin-like growth factor-1 (Igf-1), receptor activator of nuclear factor $\mathrm{kB}$ ligand (Rankl), osteoprotegerin (Opg), and collagen type 1 alpha 1 (Col1 $\alpha 1)$ were determined by quantitative real-time PCR (qRT-PCR) based on SYBR Green detection using iCycler (CFX96, Bio-Rad Laboratories). Ready-to-use primer pairs were obtained from Qiagen (QuantiTect Primer Assays). The qRT-PCR was carried out in $25 \mu \mathrm{l}$ volume containing $12.5 \mu \mathrm{l}$ QuantiTect SYBR Green PCR Kit (Qiagen), $1 \mu \mathrm{l}$ primer pairs, and $2 \mu \mathrm{l}$ cDNA. PCR profile was 1 cycle at $95^{\circ} \mathrm{C}$ for $15 \mathrm{~min}$, 40 cycles at $95{ }^{\circ} \mathrm{C}$ for $30 \mathrm{~s}, 55^{\circ} \mathrm{C}$ for $30 \mathrm{~s}$, and $72{ }^{\circ} \mathrm{C}$ for $30 \mathrm{~s}$, followed by 80 cycles at $55-95^{\circ} \mathrm{C}$ for $30 \mathrm{~s}$ where set point temperature increased after cycle 2 by $0.5{ }^{\circ} \mathrm{C}$. Amplification efficiencies for gene of interest and reference gene were around $100 \%$. Relative gene expression was calculated using $2^{-\Delta \Delta C_{\mathrm{T}}}$ method (Livak \& Schmittgen 2001) for each gene of interest, where $\Delta \Delta C_{\mathrm{T}}=\left(C_{\mathrm{T}}\right.$ treatment group gene $-C_{\mathrm{T}}$, reference gene $\beta-2$ microglobulin $(\mathrm{Mg}))-\left(C_{\mathrm{T}}\right.$ intact group gene $-\mathrm{C}_{\mathrm{T}}$, reference gene $\beta-2$ MG). In intact group $(n=10)$, male rats were intact (nonOrx, non-osteotomized, and untreated), maintained under the same conditions as the experimental animals, were of the same age, and had a comparable BW. Samples of tibia were collected from the metaphyseal part similar to that collected in osteotomized tibia. Gene expression in intact group was taken as 1 .
Statistical analyses

Statistical analyses were conducted using SAS program (Version 9.0, SAS Institute, Cary, NC, USA). ANOVA (F-test, $P<0.05)$ was applied to reveal the impact of the treatment on the respective variables. Additionally, the effect of duration was taken in the model analyzing food intake and $\mathrm{BW}$ variables. The weight of the rats was taken as a covariate to examine its effect on the variables. The effect of BW on weight of heart, liver, kidney, spleen, fat, MG, and MS was highly significant $(P<0 \cdot 001, F$-test $)$ and, therefore, organ to $\mathrm{BW}$ ratio $(\mathrm{mg} / \mathrm{g})$ was calculated and compared statistically. Differences between individual means were estimated using Scheffé test $(P<0 \cdot 05)$. Data are shown as means and S.E.M. Non-parametric Kruskal-Wallis test and Dunn's multiple comparison test were used for analyses of gene expression (GraphPad Prism 4.0, GraphPad Software, San Diego, CA, USA).

\section{Results}

\section{Serum analyses}

Serum testosterone was at the similar level among the rats at the beginning of the study (Table 1). Thereafter, it declined in all groups. In Orx rats, it dropped drastically to undetectable levels in some animals. In sham rats, testosterone level decreased gradually, but was significantly higher than that measured in Orx rats.

OC level significantly increased after PTH administration in all rats (Table 1). The highest level was measured in 'Orx PTH/ d' group. PTH applied with less frequency (Orx PTH/2d) showed less effect on OC level; however, it was still at a higher level than that in untreated rats. The activity of ALP did not change significantly after PTH treatments in all rats $(P>0 \cdot 05)$.

CK levels decreased significantly in 'Orx PTH/d' group compared with that measured in Orx, sham, and 'sham $\mathrm{PTH} / \mathrm{d}$ ' groups (Table 1). The differences in CK level between Orx and sham rats were not significant $(P>0 \cdot 05)$.

Table 1 Serum testosterone level in orchiectomized (Orx) or sham rats treated either with PTH everyday (PTH/d), every other day (PTH/2d) or given vehicle measured at the day of orchiectomy (Orx, 8 months of age), osteotomy (11 months of age), and killing (12 months of age); serum osteocalcin (OC), alkaline phosphatase (ALP), and creatine kinase (CK) levels were measured after killing. At least ten replications per treatment group were done

\begin{tabular}{|c|c|c|c|c|c|c|c|c|c|c|}
\hline & \multicolumn{2}{|l|}{ Sham } & \multicolumn{2}{|c|}{ Sham PTH/d } & \multicolumn{2}{|l|}{ Orx } & \multicolumn{2}{|c|}{ Orx PTH/d } & \multicolumn{2}{|c|}{ Orx PTH/2d } \\
\hline & Mean & S.E.M. & Mean & S.E.M. & Mean & S.E.M. & Mean & S.E.M. & Mean & S.E.M. \\
\hline \multicolumn{11}{|c|}{ Testosterone (ng/ml) } \\
\hline Orx & $2 \cdot 3^{\ddagger}$ & $0 \cdot 5$ & $2 \cdot 6^{\ddagger}$ & $0 \cdot 2$ & $2 \cdot 2^{\ddagger}$ & 0.6 & $2 \cdot 2^{\ddagger}$ & 0.6 & $2 \cdot 6^{\ddagger}$ & $0 \cdot 6$ \\
\hline Osteotomy & $1 \cdot 8^{*, \neq, \S}$ & $0 \cdot 3$ & $1 \cdot 7^{*, \neq, \S}$ & $0 \cdot 3$ & $0 \cdot 02^{t, \S}$ & $0 \cdot 004$ & $0 \cdot 03^{t, \S}$ & $0 \cdot 01$ & $0 \cdot 02^{t, \S}$ & $0 \cdot 001$ \\
\hline Killing & $1 \cdot 2^{*, \S}$ & $0 \cdot 2$ & $1 \cdot 1^{*} \S$ & $0 \cdot 1$ & $0 \cdot 02^{t, \S}$ & $0 \cdot 001$ & $0 \cdot 03^{t, \S}$ & $0 \cdot 003$ & $0 \cdot 03^{t, \S}$ & 0.002 \\
\hline $\mathrm{OC}(\mu \mathrm{g} / \mathrm{l})$ & $15^{*}$ & $1 \cdot 2$ & $47^{\|}$ & $2 \cdot 8$ & $18^{*}$ & $1 \cdot 5$ & $56^{+}$ & 2 & $31^{\pi}$ & $1 \cdot 3$ \\
\hline ALP $(\mathrm{U} / \mathrm{l})$ & 115 & 11 & 133 & 7 & 113 & 7 & 131 & 7 & 134 & 8 \\
\hline $\mathrm{CK}(\mathrm{U} / \mathrm{I})$ & $9542 *$ & 1539 & $6881 *, \|$ & 917 & $6670^{*, \|}$ & 1357 & $2847^{+}$ & 1237 & $5900^{\dagger, \|}$ & 737 \\
\hline
\end{tabular}

$*,+, \|$, Within row, between the treatment groups, means with different superscripts differ significantly $(P<0 \cdot 05$, Scheffé test). $\neq, \S$ Within column, between testosterone levels at different time points, means with different superscripts differ significantly $(P<0 \cdot 05, \mathrm{Scheffé} \mathrm{test).}$ 


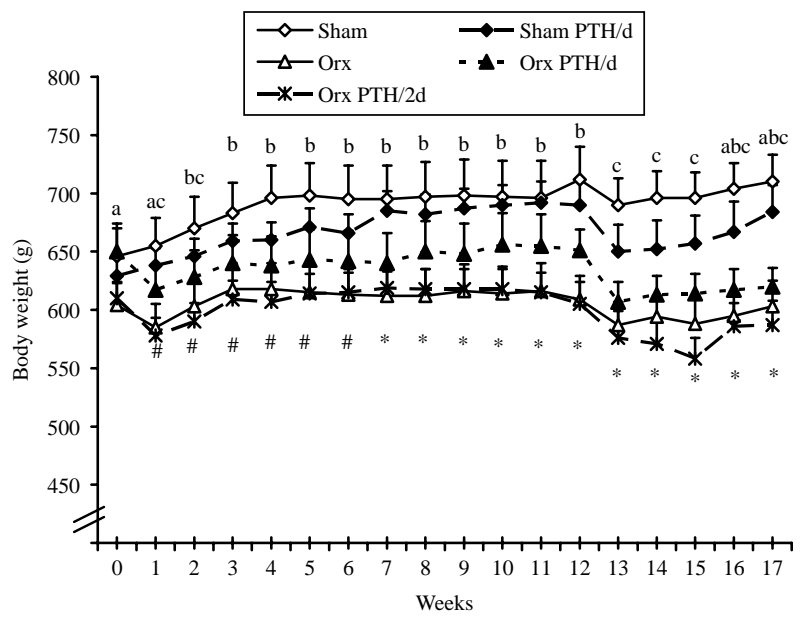

Figure 3 Body weight (g) of orchiectomized (Orx) or sham operated (week 0 ) rats which were treated after osteotomy (week 12) with PTH everyday $(\mathrm{PTH} / \mathrm{d})$ or every other day $(\mathrm{PTH} / 2 \mathrm{~d})$ or given vehicle for up to 5 weeks (week 17). Data are presented as means and S.E.M. (abc) Between weeks, means with different letters differ significantly, showed combined for all groups; $(*)$ between all sham versus all Orx, means are significantly different; (\#) between 'sham' alone versus all Orx, between 'sham PTH/d' versus Orx alone and 'Orx PTH/2d', means are different at the respective week $(P<0 \cdot 05$, Scheffé test).

\section{Food intake, BW, and organ weight}

Between the treatment groups, food intake did not differ significantly during first 9 weeks after orchiectomy (data not shown). During further weeks, Orx rats consumed less food compared to the sham animals (week 10, 24 vs 29; week 17, 25 vs $30 \mathrm{~g} /$ rat per day on average respectively).
PTH treatments did not affect food consumption $(P>0 \cdot 05)$. In all rats, a significant rise was observed in food intake during 3 weeks after orchiectomy followed by a decrease at week 4

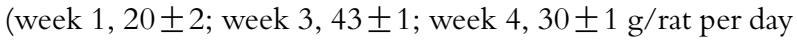
on average respectively). Thereafter, it remained without conspicuous changes to the end of the experiment with the exception of week 13 (week following osteotomy) when daily intake dropped to $16 \pm 2 \mathrm{~g}$ per day on average.

BW of Orx rats was significantly lower than that of sham rats from the first week after orchiectomy onward (Fig. 3). In group 'Orx PTH/d', BW was lower compared with that in 'sham PTH/d' group during experiment; however, the differences reached significant level from week 7. BW decreased $(P<0 \cdot 05)$ in Orx rats after orchiectomy during the first week, then rose to the initial level observed at Orx during the next 2 weeks, and remained unchanged up to week 12 (Fig. 3). The weight of sham rats continuously rose over 4 weeks and then remained without significant changes. After osteotomy (week 13), it dropped significantly in all groups, slightly recovering in sham groups and remaining at a lower level in Orx rats towards the end of the experiment. PTH treatments had no effect on BW of all rats.

Weight of heart, kidney, spleen, visceral adipose tissue, MG, and MS did not differ significantly between the groups in absolute and relative terms (Table 2). Liver was significantly heavier in sham-operated rats compared to that in Orx rats irrespective of $\mathrm{PTH}$ treatments.

\section{Muscle fibers and capillary density}

Muscle fiber size in ML and MG did not differ significantly among the groups (Table 3). In MS, cross-sectional area of

Table 2 Final wet weight of body, organs, adipose tissue, and muscles of orchiectomized (Orx) or sham rats either given vehicle or treated with $\mathrm{PTH}$ everyday $(\mathrm{PTH} / \mathrm{d})$ or every other day $(\mathrm{PTH} / 2 \mathrm{~d})$ during 5 weeks of tibia healing. At least ten replications per treatment group were done

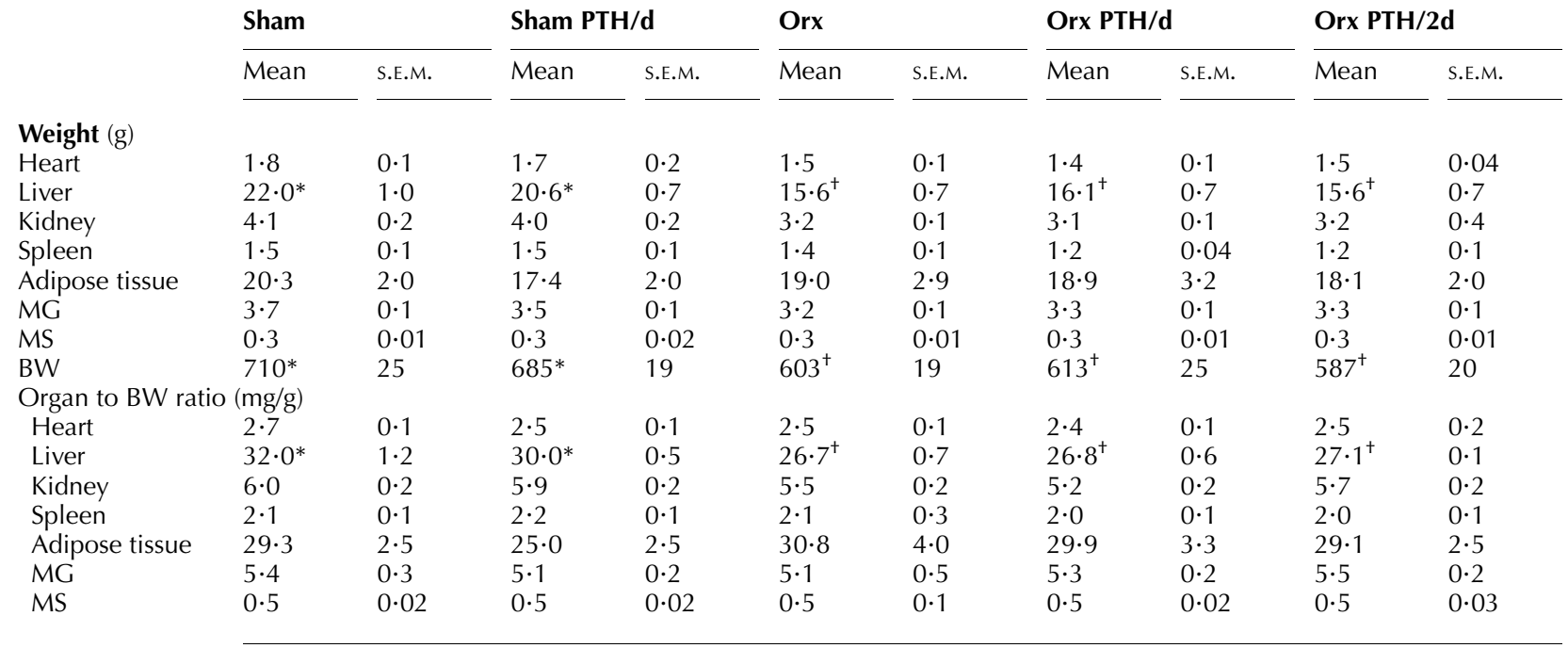

\footnotetext{
${ }^{*},{ }^{\dagger}$ Between the treatment groups, means with different superscripts differ significantly $(P<0 \cdot 05$, Scheffé test).
} 
Table 3 Cross-sectional area $\left(\mathrm{CSA}, \mu \mathrm{m}^{2}\right)$ of glycolytic $(\mathrm{G})$ and oxidative $(\mathrm{O})$ fibers, and number of capillaries per muscle fiber in gastrocnemius (MG), longissimus (ML) and soleus (MS) muscles of orchiectomized (Orx) or sham rats either given vehicle or treated with PTH everyday $(\mathrm{PTH} / \mathrm{d})$ or every other day $(\mathrm{PTH} / 2 \mathrm{~d})$ during 5 weeks of tibia healing. At least seven replications per treatment group were done

\begin{tabular}{ll} 
Sham & \\
\hline Mean S.E.M. &
\end{tabular}

Histological analyses

$\mathrm{ML}$

CSA G $\left(\mu \mathrm{m}^{2}\right)-7417$

CSA, O $\left(\mu \mathrm{m}^{2}\right) \quad 3557$

Capillaries/fiber

MS

CSA, O $\left(\mu \mathrm{m}^{2}\right)$

Capillaries/fiber

MG

CSA, G $\left(\mu \mathrm{m}^{2}\right)$

CSA, O $\left(\mu \mathrm{m}^{2}\right) \quad 3237$

Capillaries/fiber

\begin{tabular}{l} 
Sham PTH/d \\
\hline Mean S.E.M. \\
\hline
\end{tabular}

Orx

Mean S.E.M.

Orx PTH/d

Mean S.E.M.

\section{4}

2750

$1 \cdot 2$

\section{9}

208

$0 \cdot 1$

$5788^{\dagger}$

$1 \cdot 7^{+}$

412

$0 \cdot 1$

6154

3673

$1 \cdot 4^{+}$

$\begin{array}{ll}5942 & 603 \\ 2811 & 287 \\ 1 \cdot 2 & 0 \cdot 1 \\ & \\ 4826^{*} & 140 \\ 1 \cdot 6^{+} & 0 \cdot 1 \\ & \\ 5320 & 565 \\ 2747 & 200 \\ 1 \cdot 5^{+} & 0 \cdot 1\end{array}$

6183
2714
$1 \cdot 3$

$4759^{*}$
$1 \cdot 7^{+}$

5223
2358
$1 \cdot 4^{+}$

454
324
$0 \cdot 1$

268
$0 \cdot 1$

239
158
$0 \cdot 1$

6102

2594

$1 \cdot 2$

Orx PTH/2d

Mean S.E.M.

${ }^{*}{ }^{\dagger}$ Between the treatment groups, means with different superscripts differ significantly $(P<0 \cdot 05$, Scheffé test).

oxidative fibers in 'sham $\mathrm{PTH} / \mathrm{d}$ ' group was significantly larger compared to all Orx rats. Treatment with PTH had no significant effect on the size of muscle fiber in all rats $(P>0 \cdot 05)$.

Capillary density was significantly enhanced after PTH treatment in MG and MS of sham rats, reaching the level measured in Orx rats (Table 3). In Orx and 'Orx PTH/d' groups, capillary density was higher compared with that in sham group. In 'Orx $\mathrm{PTH} / 2 \mathrm{~d}$ ' group, capillary density did not differ from that in other treatment groups. In ML, there was no difference in capillary density among the groups (Table 3).

\section{Enzyme analyses}

Activity of LDH was similar among the groups: $3.8 \mathrm{U} / \mathrm{mg}$ protein in $\mathrm{ML}$ and $1.8 \mathrm{U} / \mathrm{mg}$ protein in MS on average for all animals (Table 4). CS and complex I activities did not differ significantly among the groups in both muscles studied (Table 4).

\section{Bone analyses}

Bone healing occurred at the beginning of the reparative stage: callus bridged osteotomized bone and the osteotomy line could be clearly observed (Fig. 2a-e). PTH administration resulted in a formation of larger and denser callus (Fig. 2b, d, and e) compared to that formed in untreated sham and Orx rats (Fig. $2 \mathrm{a}$ and $\mathrm{c}$ ). The osseous bridging of the osteotomy gap occurred on day 32 on average in $67 \%$ of rats in the 'sham' group, whereas, in the remaining 33\% of rats, the osteotomy was not bridged. In 'sham $\mathrm{PTH} / \mathrm{d}$ ' group, bridging was observed on day 28 on average in all rats (100\%). In 'Orx' and 'Orx PTH/d' groups, the gap was bridged on day 27 on average in $82 \%$ and $90 \%$ of rats respectively. In 'Orx PTH/2d' group, bridging was on day 29 in $73 \%$ of rats.

Callus area was larger in rats treated with PTH on a daily basis compared with that in untreated groups (Table 5). Application of PTH every other day did not change callus area significantly. Sham rats had larger osseous callus area compared with that of Orx rats.

Table 4 Activity of lactate dehydrogenase (LDH), citrate synthase (CS), and complex I in longissimus (ML) and soleus (MS) muscles of orchiectomized (Orx) or sham rats either given vehicle or treated with PTH everyday (PTH/d) or every other day (PTH/2d) during 5 weeks of tibia healing. Five replications per treatment group were done. Significant differences were not detected

\begin{tabular}{|c|c|c|c|c|c|c|c|c|c|c|}
\hline & \multicolumn{2}{|l|}{ Sham } & \multicolumn{2}{|c|}{ Sham PTH/d } & \multicolumn{2}{|l|}{ Orx } & \multicolumn{2}{|c|}{ Orx PTH/d } & \multicolumn{2}{|c|}{ Orx PTH/2d } \\
\hline & Mean & S.E.M. & Mean & S.E.M. & Mean & S.E.M. & Mean & S.E.M. & Mean & S.E.M. \\
\hline \multicolumn{11}{|l|}{ Enzymes } \\
\hline \multicolumn{11}{|l|}{$\mathrm{ML}$} \\
\hline LDH (U/mg protein) & $3 \cdot 6$ & $0 \cdot 8$ & $4 \cdot 0$ & $0 \cdot 6$ & $4 \cdot 0$ & $0 \cdot 3$ & $3 \cdot 7$ & $0 \cdot 3$ & $3 \cdot 9$ & $0 \cdot 5$ \\
\hline CS (U/g protein) & $36 \cdot 6$ & $9 \cdot 8$ & $51 \cdot 6$ & $14 \cdot 3$ & $39 \cdot 1$ & $6 \cdot 3$ & $56 \cdot 0$ & $6 \cdot 1$ & $45 \cdot 0$ & $5 \cdot 9$ \\
\hline Complex I (U/g protein) & $11 \cdot 8$ & $2 \cdot 0$ & $10 \cdot 7$ & $1 \cdot 5$ & $8 \cdot 2$ & $1 \cdot 2$ & $10 \cdot 3$ & $1 \cdot 4$ & $9 \cdot 7$ & $1 \cdot 3$ \\
\hline \multicolumn{11}{|l|}{ MS } \\
\hline LDH (U/mg protein) & $2 \cdot 0$ & $0 \cdot 1$ & $2 \cdot 1$ & $0 \cdot 3$ & $1 \cdot 7$ & $0 \cdot 1$ & $1 \cdot 8$ & $0 \cdot 2$ & $1 \cdot 6$ & $0 \cdot 1$ \\
\hline CS (U/g protein) & $75 \cdot 7$ & $15 \cdot 8$ & $87 \cdot 7$ & $20 \cdot 0$ & $82 \cdot 2$ & $13 \cdot 4$ & $96 \cdot 6$ & $12 \cdot 7$ & $90 \cdot 2$ & $4 \cdot 0$ \\
\hline Complex I (U/g protein) & $21 \cdot 4$ & $4 \cdot 6$ & $28 \cdot 9$ & $3 \cdot 0$ & $27 \cdot 8$ & $1 \cdot 2$ & $20 \cdot 9$ & $3 \cdot 9$ & $21 \cdot 3$ & $3 \cdot 8$ \\
\hline
\end{tabular}


Table 5 Flat-panel volume-computed tomographic (fpVCT) and fluorescence analyses of tibia at the osteotomy site at the ventral and dorsal aspects and endosteally in sham or orchiectomized (Orx) rats either given vehicle or treated with PTH everyday (PTH/d) or every other day $(\mathrm{PTH} / 2 \mathrm{~d})$ during 5 weeks of tibia healing. At least nine replications per treatment group were done

Sham

Mean S.E.M.

\begin{tabular}{l} 
Sham PTH/d \\
\hline Mean \\
\hline
\end{tabular}

Orx

Mean S.E.M.

\section{Parameters}

fpVCT

Ct.BMD $\left(\mathrm{mg} / \mathrm{cm}^{3}\right)$

Cl.BMD (mg/cm3)

Cl.BMD (mg/cm3) 328*

Ventral

Dorsal

Endosteal

Total

\section{$740^{*}$}

$976^{*,+}$

$4140^{*}+$

$6219^{*}$

$11334 *$

19
13
172
450
401
581

$797^{+}$
$438^{+}$
$1815^{\ddagger}$
$5021^{+}$
$6870^{*}$
$13706^{\ddagger}$

19
19
258
400
624
680

$729^{*}$
$327^{*}$
$666^{*}$
$3146^{*}$
$4502^{+}$
$8313^{+}$

$\begin{array}{ll}14 & 774^{+} \\ 8 & 448^{+} \\ & \\ 115 & 1492^{+, \neq} \\ 542 & 6738^{\ddagger} \\ 316 & 6528^{*} \\ 611 & 14758^{\ddagger}\end{array}$

Orx PTH/d

Orx PTH/2d

Mean S.E.M.

Mean S.E.M.

${ }^{*,+, \neq B e t w e e n ~ t h e ~ t r e a t m e n t ~ g r o u p s, ~ m e a n s ~ w i t h ~ d i f f e r e n t ~ s u p e r s c r i p t s ~ d i f f e r ~ s i g n i f i c a n t l y ~}(P<0 \cdot 05$, Scheffé test). BMD, bone mineral density; Ct, cortical; $\mathrm{Cl}$, callus.

Callus and cortical densities measured by fpVCT were significantly higher in all rats treated with PTH compared with those in untreated rats (Table 5). The differences between sham and Orx rats in Ct. and Cl.BMD were not significant.

In general, there were little differences in response of bone markers to PTH treatment. However, Opg, Igf-1, and Rankl gene expression changed significantly in PTH-treated rats (Fig. 4). Igf-1 and Rankl genes in 'Orx PTH/2d' group were significantly up-regulated $(P<0.05)$ comparing with those in control sham and Orx groups (Fig. $4 \mathrm{~d}$ and e). Opg gene in 'Orx PTH/d' group had significantly higher expression compared to that in the sham group (Fig. 4e). Orchiectomy had less effect on the expression of bone markers.

\section{Discussion}

PTH is a recently prescribed treatment for severe osteoporosis in women and men. However, the influence of PTH has been analyzed predominantly in females and is insufficiently investigated in males (Gagnon et al. 2008). The patients are often diagnosed as osteoporotic when the osteoporotic fractures occurred. Since the osteoporotic fractures typically occurred in the metaphysis, the metaphyseal tibia osteotomy was chosen, and bone healing was analyzed in osteopenic and healthy male rats. The study was designed to mimic the clinical situation, where osteoporotic patients would receive PTH treatment to improve bone healing. PTH treatment augments bone mass in osteoporotic patients (Gagnon et al. 2008), enhances fracture healing in experimental animals (Barnes et al. 2008, Komrakova et al. 2010), and has no adverse effect on structure of gastrocnemius muscle in 6-month-old female rats (Komrakova et al. 2010). As age-, gender-, and muscle-specific differences could be found in the response to PTH treatment, the effect of PTH on metabolic and structural properties of the two limb muscles gastrocnemius and soleus and the back muscle longissimus was analyzed. Rats display deleterious changes in bone 4 weeks after orchiectomy (Turner et al. 1989) and represent a valuable experimental model for osteoporotic studies (Wink \& Felts 1980). The clear decrease in serum testosterone verified the success of orchiectomy in the present study. A slight decrease in testosterone level also in sham-operated rats was due to aging as also indicated by Bethea \& Walker (1979).

Considering the structure of the investigated skeletal muscles, we found out that PTH and orchiectomy generally did not affect fiber size in male rats, although a decreasing influence of the orchiectomy could be found. PTH is known to increase intracellular calcium concentration in muscle tissue, which may disrupt muscle structure and exert an adverse effect on muscle metabolism (Garber 1983, Baczynski et al. 1985, Visser et al. 2003). Excess of calcium ions in sarcoplasm of organisms possessing malignant hyperthermia leads to a malignant hyperthermia crisis. If the process cannot be terminated, muscle tissue gets severely damaged (Berchtold et al. 2000). Elevated level of PTH in patients presenting hyperparathyroidism was associated with muscle weakness and reduced muscle mass (Visser et al. 2003). However, the different effect of continuous and intermittent exposure to PTH is recognized (Dobnig \& Turner 1997, Frolik et al. 2003). Continuous infusions of PTH result in severe hypercalcemia in rat. After single injection, PTH reaches its maximum serum concentration within $15 \mathrm{~min}$ and, thereafter, is cleared from the circulation within $6 \mathrm{~h}$ (Dobnig \& Turner 1997).

In the present study, BW and muscle fiber size decreased in Orx rats, whereas wet muscle weight did not change. Considering that wet muscle weight is affected by extracellular fluid accumulation and/or increased muscle fat content (Malenfant et al. 2001, McClung et al. 2006), it could be suggested that muscle tissue of Orx rats is replaced by fat tissue and water accompanied with fiber size reduction. However, further investigations are necessary.

The analysis of capillary density revealed that PTH enhanced ratio of capillaries to muscle fiber in gastrocnemius and soleus muscles in sham rats, whereas in Orx rats, PTH had 

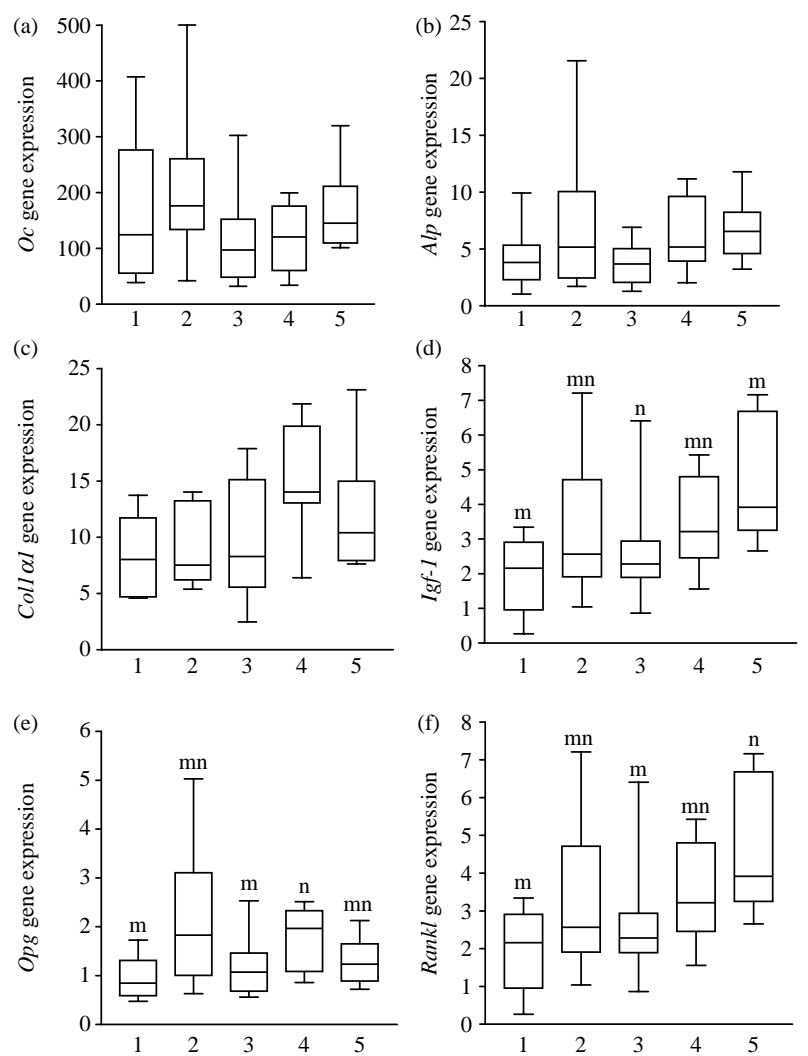

Figure 4 Box plot illustrating relative mRNA expression level of (a) Oc, (b) Alp, (c) Col1 $\alpha 1$, (d) Igf-1, (e) Opg, and (f) Rankl genes. On the X-axis, treatment groups such as (1) sham, (2) 'sham PTH/d', (3) Orx, (4) 'Orx PTH/d', and (5) 'Orx PTH/2d' are calculated using $2^{-\Delta \Delta C_{\mathrm{T}}}$ method relative to gene expression in untreated rats taken as 1. Each treatment was conducted with at least eight replications.

Medians with different letters differ significantly $(P<0 \cdot 05$, Dunn test).

minor effect. The generally higher capillary density of Orx rats compared to sham rats seems to be related to the decrease of the muscle fiber sizes. Parathyroid tissue is capable of inducing revascularization after implanting it in muscle (Wells et al. 1977). In vitro, parathyroid tissue significantly augmented angiogenesis at lower microvessel densities, whereas, at higher densities, there were no significant differences (Garter et al. 1996). Garter et al. (1996) proposed that there is equilibrium of factors that control angiogenesis. When the equilibrium is shifted towards a more angiostatic state, for instance at lower capillary density in sham group in the present study, a PTH may be capable of shifting the equilibrium towards angiogenesis. Under more angiogenic conditions, such as higher capillary density in Orx rats, PTH influence may be lost. Furthermore, angiogenesis is a complex process influenced by multiple factors that rarely occurs in the absence of disease or injury (Folkman \& Klagsbrun 1987). Wound fluid and certain prostaglandins, which levels were elevated in wounds and inflammatory exudates, have been shown to be angiogenic (Folkman \& Klagsbrun 1987). The latter might explain why the differences in capillary density were observed in the limb muscles, which were close to the surgery location at the tibia and not in the back muscle.

In the present study, a significant decrease of CK level was observed in serum of Orx rats treated with PTH everyday. The enhanced level of serum $\mathrm{CK}$ is indicative of muscle injury, myocardial infarction, muscular dystrophy, and malignant hyperthermia. CK regulates the intracellular concentration of ATP by catalyzing the generation of ATP from ADP and phosphocreatine or converts ATP into phosphocreatine. It was demonstrated that in cultured bone cells, PTH is able to increase CK activity (Sömjen et al. 1984). Reduced CK level may be found as a consequence of diminished efflux of the muscle enzyme into serum from reduced physical activity (in Orx rats) or may result from reduced muscle mass (fiber size in the present study) accompanying Orx (Rosalski 1998). Studying metabolic enzymes involved in glycolysis, citrate cycle, and oxidative phosphorylation, no adverse effect of PTH was revealed on functional cell properties and, therefore, on muscle tissue performance as well.

PTH administration increased callus area and density, as well as cortical density in both Orx and sham rats when it was applied on a daily basis, whereas, every other day application improved solely density and had no effect on callus area. In contrast, in Ovx 6-month-old female rats, PTH improved osteotomy healing irrespectively of administration regimes (Komrakova et al. 2010). Age- and gender-specific differences may be responsible for different PTH impact in bone healing. PTH has been reported to enhance osteogenesis in experimental fracture healing (Nakajima et al. 2002). PTH increased percentage of rats possessing osteotomy bridging and accelerated osteotomy bridging more in sham rats than in Orx. A similar response was observed in female rats (Komrakova et al. 2010), supporting the statement that stimulation of bone healing by PTH is more effective in healthy organisms with unaltered levels of gonadal hormones than in testosterone/ estrogen-deficient rats. Although fracture healing is supposed to be impaired in osteoporotic organisms (Namkung-Matthai et al. 2001, Stuermer et al. 2010), bone bridging in Orx rats occurred earlier than in sham rats (days 27 vs 32). Decreased callus area in Orx rats may be a consequence of diminished bone formation rate and periosteal apposition rate reported in rats after orchiectomy (Turner et al. 1989). Elevated serum OC level in all animals treated with PTH indicated increased osteoblast activity that may promote further bone synthesis and bone healing. However, enhancement of OC level was less if the PTH was applied with less frequency (everyday versus every other day). The sensitivity of serum OC to PTH-induced changes in bone turnover has been shown previously (Komrakova et al. 2010).

Interestingly, PTH administration caused up-regulation of osteoblast and osteoclast genes reaching significant levels in Orx rats (Opg, Igf-1, and Rankl mRNA gene expression). Investigating bone genes in the callus 5 weeks after osteotomy 
in 6-month-old female rats, neither PTH nor ovariectomy influenced mRNA gene expression (Komrakova et al. 2010). Based on the previous study (Meyer et al. 2003), it was suggested that changes in gene expression are measurable during early stages of healing and are not detectable 5 weeks after osteotomy. Since fracture healing takes longer in older animals (Meyer et al. 2003), it is possible that in 12-month-old rats, the healing was slowed and the differences in mRNA gene expression were still seen. Lack of androgens could additionally affect osteotomy healing and gene expression. In agreement with previous studies, mRNA expression level of $O c$ gene did not correspond to the serum level of $O c$ (Komrakova et al. 2010).

Increased muscular capillary density and in bone, earlier callus bridging, enhanced gene response to PTH in Orx rats may be an adaptation to the changes stimulated by orchiectomy (e.g. increased bone turnover) (Delmas et al. 2000, Gennary \& Bilezikian 2007).

$\mathrm{BW}$, food intake, weight of adipose tissue, visceral organs, and muscles of male rats were observed to be unaffected by PTH treatment. These data support the different effects of chronic and intermittent exposure to PTH. It is known that PTH serum level is positively correlated with BW and fat mass in humans (Bolland et al. 2006). The lower weight measured in Orx rats throughout the experiment is in agreement with earlier observations that withdrawal of androgens by orchiectomy decreases weight gain and food intake in male rats (Gentry \& Wade 1976). In our study, food intake and BW did not change in parallel. Food intake was reduced in Orx rats after week 13 onward. As previously reported, BW did not directly reflect food intake (Gentry \& Wade 1976), and some metabolic changes (Wade \& Gray 1979) and bone loss (Wink \& Felts 1980) may reduce BW in Orx rats. Orchiectomy decreases physical activity and muscle mass, and increases carcass fat content in male rats (Wade \& Gray 1979). Moreau et al. (2001) found no modification of fat mass 16 weeks after orchiectomy. In the present study, the weight of visceral adipose tissue, visceral organs and muscle did not differ significantly among the groups. Weight of the liver in sham rats was higher than that of Orx rats. Castration has been reported to reduce levels of hepatic lipids as well as liver weight (Takeuchi et al. 1986).

In summary, intermittent PTH administration had no adverse effect on enzymes involved in muscle metabolism. PTH either lowered levels of serum CK in Orx rats or did not change levels in sham rats, indicating unimpaired muscle structure and function. PTH also stimulated vascularization in limb muscles of sham rats which had lower capillary density. PTH treatment increased callus area and cortical and callus densities in all rats, improved tibia healing in sham rats, which had lower rate of osteotomy bridging and up-regulated some bone genes in the callus of Orx rats. Administration of PTH with less frequency $(\mathrm{PTH} / 2 \mathrm{~d})$ proved to be of limited success and is not recommended. PTH had no adverse effect on muscle structure, food intake, BW, nor weight of visceral adipose tissue and organs. Concluding, PTH applied daily appeared to have favorable effects on muscle tissue and bone healing in both hypogonadal and healthy male rats. However, there is concern that the changes related to the lack of androgens might blunt the effect of PTH to some extent. The findings may have important implications for therapeutic treatment of male patients.

\section{Declaration of interest}

The authors declare that there is no conflict of interest that could be perceived as prejudicing the impartiality of the research reported.

\section{Funding}

The present study was supported by the AO International Foundation (S-100).

\section{Acknowledgements}

The authors thank F Kauer, R Castro-Machguth, A Witt, and R Wigger for their help.

\section{References}

Andersen P 1975 Capillary density in skeletal muscle of man. Acta Physiologica Scandinavica 95 203-205. (doi:10.1111/j.1748-1716.1975.tb10043.x)

Armstrong RB \& Phelps RO 1984 Muscle fiber type composition of the rat hindlimb. American Journal of Anatomy 171 259-272. (doi:10.1002/aja. 1001710303)

Baczynski R, Massry SG, Magott M, El-Belbessi S, Kohan R \& Brautbar N 1985 Effect of parathyroid hormone on energy metabolism of skeletal muscle. Kidney International 28 722-727. (doi:10.1038/ki.1985.190)

Barnes GL, Kakar S, Vora S, Morgan EF, Gerstenfeld LC \& Einhorn TA 2008 Stimulation of fracture-healing with systemic intermittent parathyroid hormone treatment. Journal of Bone and Joint Surgery 90 (Supplement 1) 120-127. (doi:10.2106/JBJS.G.01443)

Berchtold MW, Brinkmeier H \& Müntener M 2000 Calcium ion in skeletal muscle: its crucial role for muscle function, plasticity, and disease. Physiological Reviews 80 1215-1265.

Bethea CL \& Walker RF 1979 Age-related changes in reproductive hormones and in Leydig cell responsivity in the male Fischer 344 rat. Journal of Gerontology 34 21-27. (doi:10.1093/geronj/34.1.21)

Bhasin S, Storer TW, Berman N, Yarasheshki K, Clevenger B \& Casaburi R 1997 Testosterone replacement increases fat-free mass and muscle size in hypogonadal men. Journal of Clinical Endocrinology and Metabolism $\mathbf{8 2}$ 407-413. (doi:10.1210/jc.82.2.407)

Bolland MJ, Grey AB, Ames RW, Horne AM, Gamble GD \& Reid IR 2006 Fat mass is an important predictor of parathyroid hormone levels in postmenopausal women. Bone 38 317-321. (doi:10.1016/j.bone.2005.08.018)

Delmas PD, Eastell R, Garnerro P, Seibel MJ \& Stephan J 2000 The use of biochemical markers of bone turnover in osteoporosis. Osteoporosis International 11 (Supplement 6) S2-17. (doi:10.1007/s001980070002)

Dobnig H \& Turner RT 1997 The effects of programmed administration of human parathyroid hormone fragment (1-34) on bone histomorphometry and serum chemistry in rats. Endocrinology 138 4607-4612. (doi:10.1210/ en.138.11.4607)

Faloona GR \& Srere PA 1969 Escherichia coli citrate synthase. Purification and the effect of potassium on some properties. Biochemistry 8 4497-4503. (doi:10.1021/bi00839a041)

Folkman J \& Klagsbrun M 1987 Angiogenic factors. Science 235 442-447. (doi:10.1126/science.2432664) 
Frolik CA, Black EC, Cain RL, Satterwhite JH, Brown-Augsburger PL, Sato M \& Hock JM 2003 Anabolic and catabolic bone effects of human parathyroid hormone $(1-34)$ are predicted by duration of hormone exposure. Bone 33 372-379. (doi:10.1016/S8756-3282(03)00202-3)

Gagnon C, Li V \& Ebeling PR 2008 Osteoporosis in men: its pathophysiology and the role of teriparatide in its treatment. Clinical Interventions in Aging 3 635-645. (doi:10.2147/CIA.S3372)

Garber AJ 1983 Effects of parathyroid hormone on skeletal muscle protein and amino acid metabolism in the rat. Journal of Clinical Investigation $\mathbf{7 1}$ 1806-1821. (doi:10.1172/JCI110936)

Garter WB, Crowell SL, Boswell CA \& Williams SK 1996 Stimulation of angiogenesis by canine parathyroid tissue. Surgery 120 1089-1094. (doi:10. 1016/S0039-6060(96)80060-2)

Gennary L \& Bilezikian JP 2007 Osteoporosis in men: pathophysiology and treatment. Current Rheumatology Reports 9 71-77. (doi:10.1007/s11926007-0025-y)

Gentry RT \& Wade GN 1976 Androgenic control of food intake and body weight in male rats. Journal of Comparative and Physiological Psychology $\mathbf{9 0}$ 18-25. (doi:10.1037/h0077264)

Hatefi Y \& Stiggall DL 1978 Preparation and properties of NADH: cytochrome $c$ oxidoreductase (complex I-III). Methods in Enzymology $\mathbf{5 3}$ 5-10. (doi:10.1016/S0076-6879(78)53005-X)

Horák V 1983 A successive histochemical staining for succinate dehydrogenase and "Reversed" - ATPase in a single section for the skeletal muscle fibre typing. Histochemistry and Cell Biology 78 545-553. (doi:10.1007/ BF00496207)

Jiang B \& Klueber KN 1989 Structural and functional analysis of murine skeletal muscle after castration. Muscle and Nerve 12 67-77. (doi:10.1002/ mus.880120113)

Komrakova M, Stuermer EK, Krischek C, Wicke M, Kolios L, Sehmisch S, Tezval M, Daub F, Martens T, Witzenhausen P et al. 2010 Effect of human parathyroid hormone hPTH (1-34) applied at different regimes on fracture healing and muscle in ovariectomized and healthy rats. Bone $\mathbf{4 7}$ 480-492. (doi:10.1016/j.bone.2010.05.013)

Larsson L \& Yu F 1997 Gender-related differences in the regulatory influence of thyroid hormone on the expression of myosin isoforms in young and old rats. Journal of Physiology 419 253-264. (doi:10.1046/j.1365-201X.1997. 559328000.x)

Livak KJ \& Schmittgen TD 2001 Analysis of relative gene expression data using real-time quantitative PCR and the $2^{-\Delta \Delta C_{\mathrm{T}}}$ method. Methods 25 402-408. (doi:10.1006/meth.2001.1262)

Malenfant P, Joanisse DR, Thériault R, Goodpaster BH, Kelley DE \& Simoneau J-A 2001 Fat content in individual muscle fibers of lean and obese subjects. International Journal of Obesity 25 1316-1321. (doi:10.1038/ sj.ijo.0801733)

McClung JM, Davis JM, Wilson MA, Goldsmith EC \& Carson JA 2006 Estrogen status and skeletal muscle recovery from disuse atrophy. Journal of Applied Physiology 100 2012-2023. (doi:10.1152/japplphysiol.01583.2005)

Meisel RL \& Sachs BD 1994 The physiology of male sexual behavior. In The Physiology of Reproduction, vol 2, pp 3-107. Eds E Knobil, JGS Neill, GS Greenwald, CL Markert \& DW Pfaff. New York: Raven Press.

Meyer RA, Meyer MH, Tenholder M, Wondracek S, Wasserman R \& Garges P 2003 Gene expression in older rats with delayed union of femoral fractures. The Journal of Bone and Joint Surgery. American Volume 85 1243-1254.

Missbach-Guentner J, Dullin C, Zientkowska M, Domeyer-Missbach M, Kimmina S, Obenauer S, Kauer F, Stühmer W, Grabbe E, Vogel WF et al. 2007 Flat-panel detector-based volume computed tomography: a novel 3D imaging technique to monitor osteolytic bone lesions in a mouse tumor metastasis model. Neoplasia 9 755-765. (doi:10.1593/neo.07466)

Moreau MF, Libouban H, Legrand E, Baslé MF, Audran M \& Chappard D 2001 Lean, fat and bone masses are influenced by orchiectomy in the rat. A densitometric X-ray absorptiometric study. Journal of Musculoskeletal and Neuronal Interactions 1 209-213.

Nakajima A, Shimoji N, Shiomi K, Shimizu S, Moriya H, Einhorn TA \& Yamazaki M 2002 Mechanisms for the enhancement of fracture healing in rats treated with intermittent low-dose human parathyroid hormone (1-34). Journal of Bone and Mineral Research 17 2038-2047. (doi:10.1359/ jbmr.2002.17.11.2038)

Namkung-Matthai H, Appleyard R, Jansen J, Hao Lin J, Maastricht S, Swain M, Mason RS, Murrell GA, Diwan AD \& Diamond T 2001 Osteoporosis influences the early period of fracture healing in a rat osteoporotic model. Bone 28 80-86. (doi:10.1016/S8756-3282(00)00414-2)

Partridge NC, Li X \& Qin L 2006 Understanding parathyroid hormone action. Annals of the New York Academy of Sciences 1068 187-193. (doi:10. 1196/annals.1346.024)

Peter JB, Barnard RJ, Edgerton VR, Gillespie CA \& Stempel KE 1972 Metabolic profiles of the three fiber types of skeletal muscle in guinea pigs and rabbits. Biochemistry 11 2627-2633. (doi:10.1021/bi00764a013)

Phillips SK, Rook KM, Siddle NC, Bruce SA \& Woledge RC 1993 Muscle weakness in women occurs at an earlier age than in men, but strength is preserved by hormone replacement therapy. Clinical Science 84 95-98.

Rahn BA 1976 The fluorochrome sequence labelling of the bone. Nova Acta Leopoldina 44 249-255.

Rosalski SB 1998 Low serum creatine kinase activity. Clinical Chemistry 44905. Schwartz-Giblin S, Rosello L \& Pfaff DW 1983 A histochemical study of lateral longissimus muscle in rat. Experimental Neurology 79 497-518. (doi:10.1016/0014-4886(83)90229-7)

Shin R \& Stern G 1967 Myopathy, osteomalacia and hyperparathyroidism. Brain 90 593-602. (doi:10.1093/brain/90.3.593)

Sömjen D, Kaye AM \& Binderman I 1984 Stimulation of creatine kinase BB activity by parathyroid hormone and by prostaglandin $\mathrm{E}_{2}$ in cultured bone cells. Biochemical Journal 225 591-596.

Streit F, Dogan A, Binder L \& Oellerich M 2007 Measurement of serum testosterone using a Waters Quattro Premier XE Micromass ${ }^{\circledR}$ system with an APPI interface. AACC Annual Meeting, San Diego, CA, USA. D-126. Abstract D-126.

Stuermer EK, Sehmisch S, Rack T, Wenda E, Seidlova-Wuttke D, Tezval M, Wuttke W, Frosch KH \& Stuermer KM 2010 Estrogen and raloxifene improve metaphyseal fracture healing in the early phase of osteoporosis. A new fracture-healing model at the tibia in rat. Langenbeck's Archives of Surgery 395 163-172. (doi:10.1007/s00423-008-0436-x)

Takeuchi N, Go S, Murase M, Nomura Y, Takase H \& Uchida K 1986 Effects of castration and testosterone administration on serum lipoproteins and their apoproteins in male spontaneously hypertensive rat. Endocrinology 118 1787-1794. (doi:10.1210/endo-118-5-1787)

Turner RT, Hannon KS, Demers LM, Buchanan J \& Bell NH 1989 Differential effects of gonadal function on bone histomorphometry in male and female rats. Journal of Bone and Mineral Research 4 557-563. (doi:10. 1002/jbmr.5650040415)

Visser M, Deeg DJH \& Lips P 2003 Low vitamin D and high parathyroid hormone levels as determinants of loss of muscle strength and muscle mass (sarcopenia): the longitudinal aging study Amsterdam. Journal of Clinical Endocrinology and Metabolism 88 5766-5772. (doi:10.1210/jc.2003-030604)

Wade GN \& Gray JM 1979 Theoretical review. Gonadal effects on food intake and adiposity: a metabolic hypothesis. Physiology and Behavior 22 583-593. (doi:10.1016/0031-9384(79)90028-3)

Wells SA, Stirman JA \& Bolman RM 1977 Parathyroid transplantation. World Journal of Surgery 1 747-756. (doi:10.1007/BF01555931)

Wink CS \& Felts WJL 1980 Effects of castration on the bone structure of male rats: a model of osteoporosis. Calcified Tissue International 32 77-82. (doi:10. 1007/BF02408524)
Received in final form 7 January 2011
Accepted 13 January 2011
Made available online as an Accepted Preprint 13 January 2011 